

\title{
Editorial
}

\section{Developing a research culture in paramedic practice}

\author{
Scott Devenish, BN, DipParaSc, MVEdT, PhD, Fellow ${ }^{1}$ and Director of International Engagement and Recruitment ${ }^{2}$
}

\author{
Affiliations: \\ ${ }^{1}$ Australian and New Zealand College of Paramedicine \\ ${ }^{2}$ School of Clinical Sciences, Faculty of Health, Queensland University of Technology
}

As paramedic practice in Australasia transitions toward professional registration, it is timely to examine the importance of developing a research culture within the profession. The benefits of a research culture may include improving patient care, and increasing in the paramedic professional image (1). Challenges possibly include the perception that performing research may be difficult in a time-critical environment (1) and the ambulance service culture, under a vocational in-house education and training model, may traditionally not have sought out new research opportunities or encouraged paramedics to undertake research studies.

The 'academisation' of the paramedic profession has subsequently resulted in a greater emphasis being placed in research. For example, the Council of Ambulance Authorities has created a research forum which facilitates research into ambulance operations and clinical practice (2). Furthermore, there are scholarships and incentive schemes offered by most Australasian ambulance services to encourage paramedics to engage in research. However, developing a National Ambulance Research Steering Group in Australasia may possibly further assist to develop a research culture. For example, in the United Kingdom, the National Ambulance Research Steering Group was formed to facilitate a strategic approach between ambulance services, professional bodies and university paramedic programs to further develop a research culture and increase capacity and capability for highquality research (3).

The decision to implement undergraduate tertiary qualifications for new entrants to the profession in Australasia is also beginning to pay dividends with an increasing number of paramedics choosing to engage in research as well as postgraduate studies and higher degrees in research, which is a positive sign for the profession. As such, university paramedic programs are playing an important role in developing a research culture by placing an emphasis on research in the undergraduate course curriculum (4). The course curriculum is part of the paramedic professional socialisation process, and provides university paramedic students with the values, behaviours, knowledge and skills required to join the paramedic profession $(5,6)$. By emphasising the importance of research to the profession during undergraduate studies, graduates are encouraged and prepared to engage in research during their paramedic careers.

Professional associations such as Paramedics Australasia (PA) are further encouraging the development of a research culture. In addition to its scientific agenda, PA provide an interface between the profession and university paramedic programs though organising student paramedic activities, such as the recent Student Paramedics Australasia (SPA) conference held at the Australian Catholic University Paramedic Program campus in North Sydney.

Poster abstracts are presented from the SPA conference in this issue of AJP, and can be categorised into themes addressing clinical, research and professional identity topics. In the clinical category, posters addressed topics such as hand dominance in external chest compressions (7), aeromedical aspects of paramedicine $(8,9)$ chronic obstructive pulmonary disease (10) and inferoposterolateral myocardial infarction (11). In the research category, posters presented topics such as introducing student to research (12), identifying student attitudes toward research (13) and investigating how to get students involved in research (14). In the professional identity category, posters topics covered the transition to professional practice (15) and the development a professional student identity (16). 
Today's students are the future paramedic leaders, educators and researchers (17). Through the quality of these poster presentations, it is clear that university paramedic programs, professional groups and the profession are working together with a common goal of developing a research culture. However, the engagement between universities, professional bodies and the profession may benefit further from a research steering group to strategically strengthen and consolidate an Australasian paramedic research culture.

Dr Scott Devenish

Queensland University of Technology

\section{References}

1. Watson DLB, Sanoff R, Mackintosh JE, et al. Evidence from the scene: paramedic perspectives on involvement in out-ofhospital research. Ann Emerg Med 2012;60:641-50.

2. Council of Ambulance Authorities. The CAA Committees: Research Forum: Council of Ambulance Authorities; n.d. Available at: www.caa.net.au/about-us/the-committees\#research-forum [Accessed 23 October 2016].

3. Siriwardena AN, Donohoe R, Stephenson J, Phillips P. Supporting research and development in ambulance services: research for better health care in prehospital settings. Emerg Med J 2010;27:324-6.

4. Garde-Hansen J, Calvert B. Developing a research culture in the undergraduate curriculum. Active Learning in Higher Education 2007;8:105-16.

5. Devenish S, Clark M, Fleming M. Experiences in Becoming a Paramedic. Creative Education 2016;7(6).

6. Devenish AS. Experiences in Becoming a Paramedic: A Qualitative Study Examining the Professional Socialisation of University Qualified Paramedics. Brisbane: Queensland University of Technology; 2014. Available at: http:/leprints.qut.edu. au/78442/

7. Arndell J, Lam T, Cross J, et al. Impact of hand dominance on effectiveness of external chest compressions: A randomised crossover trial. SPA Conference; 30 Sept - 1 Oct; Australian Catholic University, Nth Sydney: Paramedics Australasia; 2016.

8. Delorenzo A, Shepherd M, Jennings P. Endotracheal cuff pressure changes during HEMS transport. A systematic review. SPA Conference; 30 Sept - 1 Oct; Australian Catholic University, Nth Sydney: Paramedics Australaisa; 2016.

9. Delorenzo A, Abetz J, Andrew E, de Wit A, Williams B, Smith K. Characteristics of Fixed-Wing Air Ambulance Transports in Victoria, Australia. SPA Conference; 30 Sept - 1 Oct; Australian Catholic University, Nth Sydney: Paramedics Australasia; 2016.

10. Matthew A. Chronic Obstructive Pulmonary Disease. SPA Conference; 30 Sept - 1 Oct; Australian Catholic University, Nth Sydney: Paramedics Australasia; 2016.

11. Whytcross M. Inferoposterolateral ST Elevation Myocardial Infarction (STEMI). SPA Conference; 30 Sept - 1 Oct; Australian Cathoolic Univeristy, Nth Sydney: Paramedics Australasia; 2016.

12. Webley D. Inspired by Campeau: A pathway through undergraduate paramedic research. SPA Conference; 30 Sept - 1 Oct; Australian Catholic University: Paramedics Australasia; 2016.

13. Glenn T, Phillips D, Plews L. Hook, Line and Sinker Introducing Paramedic Students To The World Of Research. SPA Conference; 30 Sept - 1 Oct; Australian Catholic University, Nth Sydney: Paramedics Australasia; 2016.

14. Stack H, Graham S, Johnston T. Getting Involved in Research: A Student's Perspective. SPA Conference; 30 Sept - 1 Oct; Australian Catholic University, Nth Sydney: Paramedics Australasia; 2016.

15. Hicks G. Leaving The Nest: Australian Paramedic Student's Perceptions of their Future Transition to Paid Employment. SPA Conference; 30 Sept - 1 Oct; Australian Catholic University, Nth Sydney: Paramedics Australasia; 2016.

16. Stack H, Graham S, Johnston T. Investigating Student Paramedic Professional Identity. SPA Conference; Australian Catholic University, Nth Sydney: Paramedics Australasia; 2016. p. 30 Sept - 1 Oct.

17. O'Meara P. Student research: the future of paramedicine. Australasian Journal of Paramedicine 2014;11(5). 